\title{
Ovarian cancer aetiology: facts and fiction
}

\author{
Karim Elmasry, Simon A Gayther
}

\section{Introduction}

Primary carcinoma of the ovary is the fourth most common cancer among women in the UK; there were almost 7000 new cases reported in 1999, which equates to a lifetime risk for women of $2 \%$. In addition, ovarian cancer is the fifth most common cause of deaths in women, with more than 4500 deaths from the disease every year. ${ }^{1}$

The natural history of ovarian cancer development, including the nature of the precursor cell type, is poorly understood. This is somewhat surprising given the extensive published research literature on the subject. Approximately $90 \%$ of malignant ovarian tumours are epithelial in origin; the remainder are germ cell tumours. Various theories have been suggested as to how ovarian cancers develop. These include the incessant ovulation theory, ${ }^{2}$ the gonadotrophin theory ${ }^{3,4}$ and the retrograde transportation hypothesis. 5

The incessant ovulation theory suggests that the risk of ovarian carcinoma increases as a result of the recurrent minor trauma to the ovarian surface epithelium that occurs during ovulation. The suggestion is that the greater the number of times the ovarian surface epithelium undergoes trauma, the greater the chance will be that aberrations leading to a malignant transformation will occur.

The gonadotrophin theory suggests that high levels of gonadotrophins, especially in the early menopausal years, are associated with an increased risk of ovarian cancer as a result of oestrogen or oestrogen precursors stimulating the ovarian surface epithelial lining of ovarian inclusion cysts. Inclusion cysts are benign vacuoles that can form and embed in the ovarian stroma following repair to the ovarian surface epithelium. Histologically, the epithelial lining of these cysts appears normal.

Finally, the retrograde transport hypothesis suggests that certain carcinogenic factors gain access from the uterus through the Fallopian tubes to the ovaries, thereby increasing the risk of ovarian cancer

All of these theories have been plausibly supported by data from epidemiological studies, but no single theory seems more convincing than any other. Similarly, our understanding of the molecular or genetic events that underlie ovarian cancer formation, which could go some way towards providing support for or refuting these theories, are also poorly understood. 6

The purpose of this article is to clarify and review the current understanding of the aetiology of ovarian cancer including the factors that influence disease risk and the prognostic importance of screening for preclinical disease in the absence of a precancerous lesion.

J Fam Plann Reprod Health Care 2006; 32(2): 82-86 (Accepted 21 December 2005)

Translational Research Laboratories, Department of Gynaecological Oncology, Windeyer Institute, London, UK Karim Elmasry, BSc, MRCOG, Clinical Research Fellow Simon A Gayther, BSc, PhD, Senior Lecturer

Correspondence to: Dr Karim Elmasry, Translational Research Laboratories, Department of Gynaecological Oncology, Windeyer Institute, Cleveland Street, London W1T 4JF, UK Tel: +44 (0) 207679 9329. Fax: +44 (0) 2076799243.

E-mail: k.elmasry@ucl.ac.uk

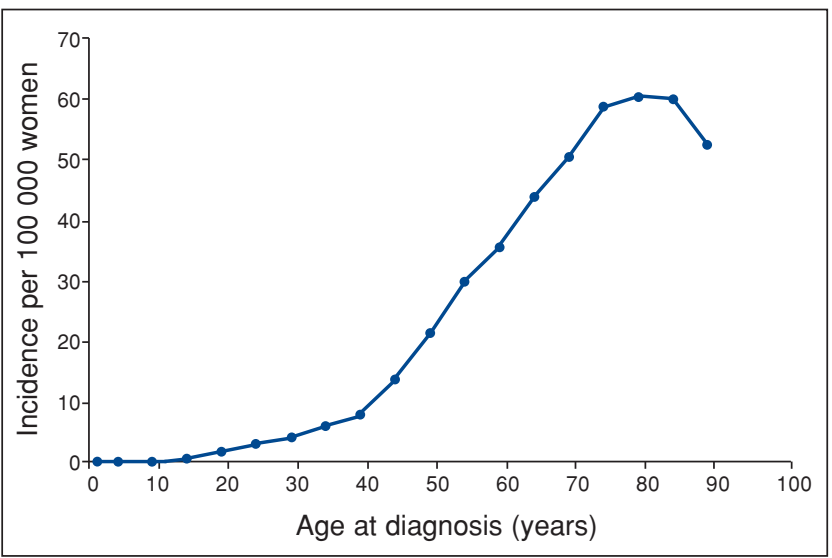

Figure 1 Age-associated incidence of epithelial ovarian cancer (data from the Surveillance Epidemiology and End Results Program of the National Cancer Institute ${ }^{7}$ )

\section{Epidemiological and genetic risk factors \\ Age}

There is a progressive increase in ovarian cancer incidence with age. For epithelial ovarian tumours, the risk of disease in women under the age of 30 years is low even in families with evidence of a hereditary basis of ovarian cancer. From 30 to 50 years of age, ovarian cancer incidence rises in a linear fashion. It then continues to increase, albeit at a lower rate, reaching a maximum incidence of 60.5 per 100000 women in the 75-79 years age group (data from the Surveillance Epidemiology and End Results Program of the National Cancer Institute ${ }^{7}$ ) (Figure 1).

\section{Geography}

Ovarian cancer incidence varies widely across different geographical regions and ethnic groups ${ }^{8}$ (Figure 2). The highest incidence is in Northern Europe (14.5 cases per 100000 women in Sweden) and the USA (13.3 cases per 100000 women); the lowest incidence is in Japan (2.7 cases per 100000 women). As with other cancers, there are obvious increases in risk in populations that migrate from a country with low risk to a country of higher risk, indicating a possible role for dietary and environmental factors.

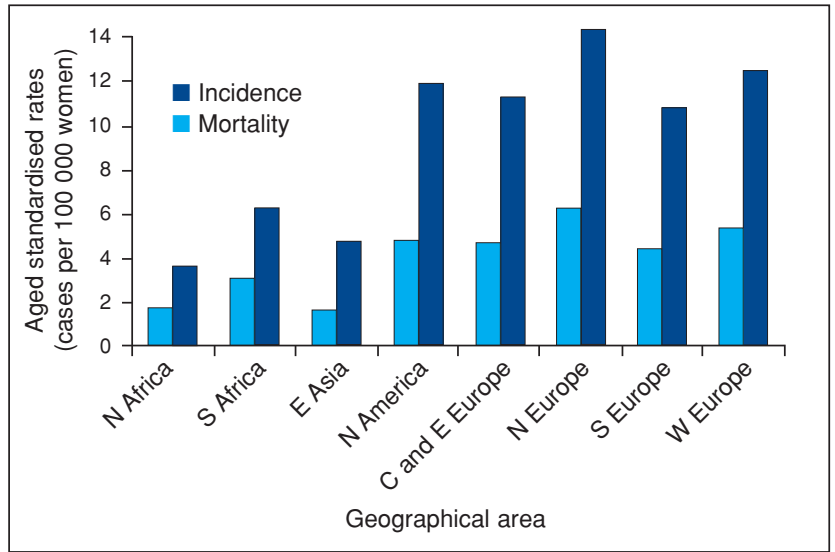

Figure 2 Geographical variation in incidence and mortality rates for epithelial ovarian cancer (data from the GLOBOCAN 2002 database project hosted by the Descriptive Epidemiology Group at the International Agency for Research on Cancer $^{8}$ ) 


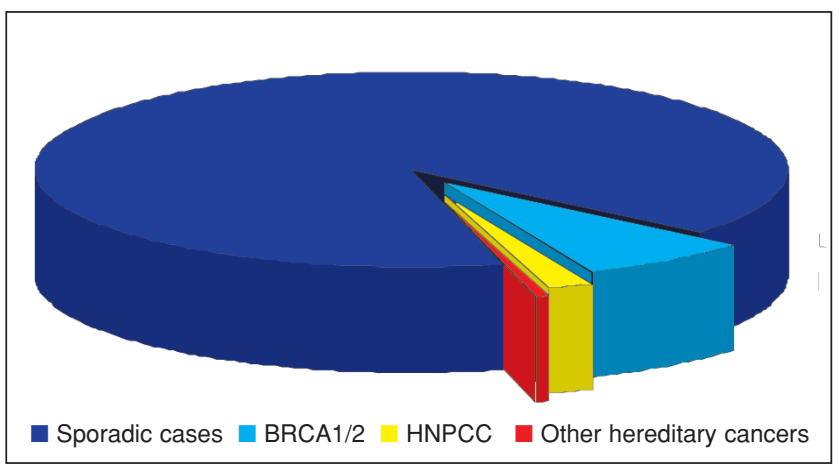

Figure 3 The contribution of high-risk susceptibility genes to the epithelial proportion of ovarian cancer. HPNCC, hereditary nonpolyposis colorectal cancer

\section{Family history}

The majority of ovarian cancer cases are sporadic. However, $5-10 \%$ of cases have a hereditary basis (i.e. they are familial). Despite this, the single greatest ovarian cancer risk factor is a family history of the disease; the relative risk of ovarian cancer in a woman with an affected first-degree relative is 3.1 (95\% CI 2.6-3.7). The level of ovarian cancer risk is correlated with the number of affected first- and second-degree relatives and the age at diagnosis: the highest risk is associated with women below the age of 50 years who have a first-degree affected relative aged under 50 years.

There are at least two groups of individuals with a hereditary predisposition to ovarian cancer for which pedigree analyses suggest autosomal-dominant transmission with variable penetrance. Families with BRCA1 and BRCA2 mutations comprise approximately 90\% of families with a strong history of ovarian cancer (more than three cases in first-degree relatives) or multiple cases of ovarian and breast cancer (Figure 3). The lifetime risk of developing ovarian cancer for BRCA1 carriers is $16-44 \%$ and for BRCA2 carriers is $27 \% .^{9-12}$

Ovarian cancer is also part of the phenotype of hereditary non-polyposis colorectal cancer (HNPCC) syndrome (alternatively known as the Lynch syndrome), which is commonly associated with inherited susceptibility to colorectal, gastric and endometrial cancers. The lifetime risk of ovarian cancer for a carrier in a HNPCC family is about $10 \% .{ }^{13}$ HNPCC families are caused by mutations in one of several genes that function in DNA mismatch repair pathways.

High-risk genes that cause ovarian cancer are rare and are responsible for only $30 \%$ of the excess familial ovarian cancer risk. It is likely that the remaining familial risks are the result of more common but less penetrant genetic variation (moderate-risk genes), however these genes await identification.

\section{Reproductive and hormonal factors \\ Early menarche and late menopause}

There have been several epidemiological studies that have looked at age at menarche as a risk factor for ovarian cancer. In general, these have found no association. ${ }^{14-18}$

Although no association has been found between age at menopause and ovarian cancer risk in most studies, ${ }^{16-19}$ a small number of studies have suggested that late menopause may increase risk, with estimates ranging from 1.5- to 2.9-fold increased risks in the oldest menopause groups compared with younger referents. ${ }^{15,18,20}$

\section{Parity}

Epidemiological studies have continually shown that parity is protective against ovarian cancer. Whittemore et al. ${ }^{16}$ reviewed 12 case-control studies and showed that parity has a significantly protective effect against ovarian cancer; there was an approximately $40 \%$ reduction in risk with first birth and a further reduction of $10 \%$ with each subsequent birth.

There may also be an association with the age at first birth, although this is less clear. Some hospital-based studies suggest that an older rather than younger age at first birth is more protective, $16,18,20$ but case-control studies with population-based controls indicate the reverse is true. $15,21,22$

Whilst the impact of term pregnancies on the ovarian cancer risk is clear, the effect of miscarriages, terminations and ectopic pregnancies is not. A case-control study from Denmark found no relationship between ovarian cancer and pregnancies that fail to proceed to term. ${ }^{23}$ However, other studies suggest that incomplete pregnancies confer some risk reduction, albeit a weaker protective effect than that of full-term pregnancies. ${ }^{17,18,22}$

\section{Lactation}

Most studies that have separated the effects of breastfeeding from pregnancy have demonstrated a small protective effect from lactation. Risk estimates range from between 0.6 and 0.9 in parous women who have breastfed their children compared with those who have never breastfed. $16,22,24,25$

\section{Combined oral contraceptive pill}

Based on a large body of epidemiological studies, it is now accepted that the combined oral contraceptive pill (COC) protects against ovarian cancer. The cause of this protective effect has been ascribed to the cessation of ovulation and/or the decrease in gonadotrophin levels in mid-cycle. In casecontrol and prospective studies, 'ever' users of COCs have been shown to have a lower risk compared to 'neverusers'. $15-17,20,22,26,27$ The protective effect increases with duration of COC use; there is a $10-12 \%$ decrease in risk associated with a 1-year COC use 28 and an approximate $50 \%$ decrease after 5 years of use. ${ }^{29}$ The risk reduction associated with $\mathrm{COC}$ use continues for a long time after cessation of the COC; several studies showed a 40-70\% risk reduction even 10 years after cessation of COC use. $15,16,20,27$ One recent study even suggested a risk reduction after 25 years of COC use. 15

COCs confer a protective effect regardless of other known risk factors such as parity or age. ${ }^{26-28}$ However, there does appear to be an additive effect for parity and COC use combined; Franceschi et al. found that women who have two children and have taken the COC for $\geq 5$ years had a $70 \%$ risk reduction for ovarian cancer. ${ }^{30}$

The risk reduction for COC use may also be associated with different histological subtypes of ovarian cancer. In a case-control study that examined the effect of COC use on the risk of mucinous and non-mucinous ovarian cancer, Risch et al. found that the risk of mucinous ovarian cancer was not reduced in women on COCs. 31

There are a wide variety of COCs with differing oestrogen and progestin content. The initial COCs of the 1960s were high-dose monophasic formulations. Hormonal doses were then reduced in the 1970s, and in the 1980s biphasic and triphasic formulations were introduced. The majority of studies showing the protective role of COCs were based on women using the early monophasic formulations. The protective effect appears to be present in newer formulations also; use of one of two types of lowdose COC formulations ( $\leq 35 \mu \mathrm{g}$ ethinylestradiol) compared to never-users was associated with a reduced relative risk of ovarian cancer of 0.7 and 0.4 , respectively, and there was a risk reduction with multiphasic COCs 


\section{REVIEW}

also. ${ }^{26}$ In another study, in which both high- and low-dose COCs reduced the risk of ovarian cancer, the high-dose regimen appeared slightly more effective. 32

A few studies that have evaluated the effect of progestogen-only contraceptives on ovarian cancer suggest a protective effect. In a study of 5000 women receiving medroxyprogesterone injections with 4-13 years' followup, there was an insignificant decrease in ovarian cancer risk [relative risk (RR) $0.8,95 \% \mathrm{CI} 0.1-4.6$ ].33

The association between COC use and ovarian cancer risk in women who are BRCA carriers has also been studied. In a population-based study, no association was observed between oral contraceptive use and risk reduction in high-risk women. ${ }^{34}$ However, in a family-based study, a $60 \%$ risk reduction was observed in women with BRCA mutations who had been on the pill for 6 or more years. ${ }^{35}$ More recently, in a study of 451 BRCA1/2 mutation carriers, the odds ratio (OR) for ovarian cancer associated with the use of oral contraceptives for 6 or more years was 0.62 (95\% CI $0.35-1.09)$ after adjusting for parity. ${ }^{36}$

\section{Infertility}

In 1992, a collaborative analysis of 12 case-control studies in the USA reported that the risk of ovarian cancer in nulliparous women who received fertility treatment was increased 27-fold. However, this finding should be treated with caution for two reasons. First, the confidence intervals for this study were wide (95\% CI 2.3-315.6). ${ }^{16}$ Second, the individual studies that made up the collaborative analysis differed vastly in the depth with which the relevant information was collected; only 3/12 studies contained results regarding infertility therapy. Since this report, a further two case-control studies have failed to find an association between fertility drug use and ovarian cancer. ${ }^{37,38}$ A number of cohort studies of women undergoing fertility treatment have also failed to demonstrate an increased ovarian cancer risk associated with infertility. ${ }^{39-41}$ In the largest of these studies, the excess risk of ovarian cancer was observed in women with unexplained fertility who had not had any fertility drugs. ${ }^{41}$

The are several difficulties in study design that make this a difficult question to address, and this may be responsible for some of the disparity observed between studies For example, it is unclear whether the risk of ovarian cancer increases as women come to an age where ovarian cancer is more common, which coincides with the timing of infertility treatment. In addition, for case-control studies, there are problems associated with defining the 'infertility type', the different types of fertility drugs used and in the selection of an appropriate control group.

\section{Hormone replacement therapy}

Issues relating to the use of hormone replacement therapy (HRT) and its safety continue to challenge clinicians.

HRT initially contained oestradiol or conjugated oestrogens only. It then became apparent in the 1970s that the use of oestrogen (estrogen) replacement therapy (ERT) was associated with an increased risk of endometrial cancer. As a result, progestins were added to the ERT in women with an intact uterus. ERT, however, continues to be used in women who have undergone a hysterectomy.

Studies on the effect of ERT/HRT on the risk of ovarian cancer are contradictory. In a recent cohort study that followed 44241 menopausal women for approximately 20 years, a relative risk of 1.6 (95\% CI 1.2-2.0) was observed among ever-users compared with never-users of ERT. ${ }^{42}$ The largest risk observed in this study was for women who used ERT for 20 years or more, for whom the RR was 3.2 (95\% CI 1.7-5.7). In another study, there was an increased risk of ovarian cancer associated with ERT of 10 or more years..$^{43}$

Until recently, many of the studies that examined the effect of combined HRT on ovarian cancer risk have been too small to draw firm conclusions. One such study suggested that HRT did not increase the risk of ovarian cancer if progestin was used for more than 15 days per month. ${ }^{44}$ The largest trial so far on the effect of HRT on ovarian cancer risk is the Women's Health Initiative. ${ }^{45}$ In this double-blind, randomised control trial approximately 17000 women were randomised to either combined HRT or placebo. After an average 5.6 years of follow-up, there was a non-statistically significant increase in ovarian cancer risk in users of HRT compared to the placebo group (hazard ratio $1.58,95 \%$ CI $0.77-3.24$ ).

\section{Other factors}

\section{Talcum powder}

There is some evidence to suggest that agents that irritate and inflame the ovarian epithelium promote ovarian carcinogenesis. This theory arose from observations that asbestos was associated with mesotheliomas in animals 46 and that particle passage from the vagina to the ovary was possible. ${ }^{47}$ Talcum powder use in the genital area has been postulated to increase the risk of ovarian cancer by ascending the genital tract. This theory has been supported in a case control study 47,48 that gave an OR of $1.6(95 \% \mathrm{CI}$ $1.18-2.15)$ and that talcum powder use was associated serous and undifferentiated tumours.

\section{Pelvic surgery}

The association between pelvic surgeries such as tubal ligation and hysterectomy and ovarian cancer has been reported in a number of epidemiological studies. Although the Oxford Family Planning Association study showed no association between sterilisation and ovarian cancer (OR $1.5,95 \%$ CI $0.7-3.1]),{ }^{49}$ the majority of studies support a protective effect with observed risk reductions from $10 \%$ to $80 \% .50-53$

A similar protective effect was observed in women who underwent hysterectomy, although the magnitude of protection appears to be lower than that of tubal ligation. ${ }^{50-53}$

Both these operations provide closure of the ovaries to the external genital tract, and it has been suggested that these operations reduce the risk of ovarian cancer by preventing carcinogens from ascending the genital tract. It is, however, interesting that the protective effect has been reported only up to 20 years after surgery.

\section{Endometriosis}

Pathology and epidemiological studies have consistently shown an association between endometriosis and ovarian cancer, particularly of the endometrioid subtype ${ }^{54,55}$ and clear cell ${ }^{54}$ subtypes of ovarian cancer. Histopathology studies analysing large series of ovarian tumours have identified ovarian endometriotic lesions in 5-10\% of cases. ${ }^{56}$ These were most commonly found in tumours of the endometrioid (up to 60\%) and clear cell (up to 15\%) subtypes, which is disproportionate to the expected frequencies of these subtypes of ovarian cancer (10-20\% and $3-10 \%$, respectively). In another study, endometriosis was found in $40 \%$ of women with Stage I endometrioid or clear cell carcinoma, one-third of which were carcinomas arising out of the endometriotic lesions. Two theories have been proposed for the transformation of endometriosis to ovarian cancer. First, aberrant inflammation may serve to promote the growth and invasion of ectopic endometrium. Second, it has been postulated that the same balance of steroid hormones that has been shown to increase the 
severity of endometriosis may also enhance the occurrence of ovarian cancer.

\section{Polycystic ovarian syndrome}

Clinical features of polycystic ovarian syndrome (PCOS) commonly include obesity, infertility, menstrual abnormalities and hirsutism. In addition, PCOS is also characterised by a raised luteinising hormone to folliclestimulating hormone, increased androgen production and abnormal oestrogen secretion. There is a well-established relationship between PCOS and endometrial cancer risk, but the risks associated with ovarian cancer are less clear. In a case-control study, 57 the risk of ovarian cancer was increased in women with PCOS (OR 2.5, 95\% CI 1.1-5.9) and the risk was greater in women who had not used the COC (OR 10.5, 95\% CI 2.5-44.2). Other studies, however, found no association between PCOS and ovarian cancer. 58

\section{Pelvic inflammatory disease}

Pelvic inflammatory disease (PID) can arise as a complication of sexually transmitted infections or after childbirth, terminations and gynaecological procedures. Whilst some studies have found a positive association between PID and the risk of ovarian cancer, ${ }^{59}$ others have not. ${ }^{17,51,60}$ In a Canadian study, there was an increased risk of ovarian cancer with one episode of PID compared to those with none (OR 1.5, 95\% CI 1.0-2.1). Risks were also greater if PID had occurred at an earlier age, if the women were nulliparous, infertile or had repeated episodes of PID. ${ }^{59}$ Despite the association between human papilloma virus (HPV) and cervical cancer, no association has been found with ovarian cancer. ${ }^{61,62}$

Diet

Diet may affect ovarian cancer risk, but there appears to be no consensus about which dietary factors may be causative or protective. Several studies have suggested a link between one or more of lactose, animal fat, meat, egg and cholesterol intake with an increased risk of ovarian cancer. ${ }^{63,64}$ conversely, a high consumption of vegetables and olive oil may decrease risk. ${ }^{64-66}$ A systematic review of 11 population-based case-control studies and five cohort studies ${ }^{66}$ showed a positive association between body size and ovarian cancer risk, which is of course associated with dietary and calorific intake. These findings have been confirmed in more recent studies. ${ }^{68-72}$

\section{Conclusions}

Based on several epidemiological studies, there is good evidence that increased parity, use of the COC, and tubal ligation and hysterectomy reduce the risk of ovarian cancer. Other factors such as lactation, age at menarche and age at menopause seem to have a weaker effect on risk reduction. The effects of endometriosis, infertility treatment and PCOS on ovarian cancer risk remain unclear.

Despite this understanding of the epidemiological factors that affect ovarian cancer risk, the underlying cellular, biological and molecular genetic bases that may be influenced by these factors remains poorly understood. One of the future challenges will be to study more completely the interactions between environmental and molecular biological events that cause or protect against ovarian cancer. It is likely that a better understanding of these factors will lead to clear clinical benefits in terms of prevention (as in the case of cervical cancers and HPV vaccines), early detection and treatment of the disease.

Editor's Note

A second article on ovarian cancer screening will appear in the July 2006 issue of the Journal
Statements on funding and competing interests

Funding. None identified.

Competing interests. None identified.

References

1 Office of National Statistics. Cancer Statistics: Registrations 2001. London, UK: HMSO, 2001. http://www.statistics.gov.uk/downloads/ theme health/MB1_32/MB1_32.pdf [Accessed 16 December 2006].

2 Fathalla MF. Incessant ovulation - a factor in ovarian neoplasia? Lancet 1971; 2: 163

3 Cramer DW, Welch WR. Determinants of ovarian cancer risk. II. Inferences regarding pathogenesis. J Natl Cancer Inst 1983; 71: $717-721$.

4 Stadel BV. The etiology and prevention of ovarian cancer (Letter). Am J Obstet Gynecol 1975; 123: 772-774.

5 Cramer DW, Xu H. Epidemiologic evidence for uterine growth factors in the pathogenesis of ovarian cancer. Ann Epidemiol 1995; 5: 310-314.

6 Elmasry K, Gayther SA. Somatic genetic mutations and clinical outcome in gynaecological cancers. Gynaecol Forum 2005; 10: 5-11.

7 Surveillance Epidemiology and End Results (SEER) Program of the National Cancer Institute, National Cancer Institute, US National Institutes of Health, Bethesda, MD, USA. http://seer.cancer.gov/ [Accessed 16 December 2005].

8 GLOBOCAN 2002 database project hosted by the Descriptive Epidemiology Group, International Agency for Research on Cancer, Lyon, France. http://www-dep.iarc.fr/ [Accessed 16 December 2005].

9 Struewing JP, Hartge P, Wacholder S, Baker SM, Berlin M, McAdams $\mathrm{M}$, et al. The risk of cancer associated with specific mutations of BRCA1 and BRCA2 among Ashkenazi Jews. N Engl J Med 1997; 336: $1401-1408$.

10 Whittemore AS, Gong G, Itnyre J. Prevalence and contribution of BRCA1 mutations in breast cancer and ovarian cancer: results from three US population-based case-control studies of ovarian cancer. Am J Hum Genet 1997; 60: 496-504.

11 Ford D, Easton DF, Bishop DT, Narod SA, Goldgar DE. Risks of cancer in BRCA1-mutation carriers. Breast Cancer Linkage Consortium. Lancet 1994; 343: 692-695.

12 Ford D, Easton DF, Stratton M, Narod S, Goldgar D, Devilee P, et al. Genetic heterogeneity and penetrance analysis of the BRCA1 and BRCA2 genes in breast cancer families. Breast Cancer Linkage Consortium. Am J Hum Genet 1998; 62: 676-689.

13 Aarnio M, Mecklin JP, Aaltonen LA, Nystrom-Lahti M, Jarvinen HJ. Life-time risk of different cancers in hereditary non-polyposis colorectal cancer (HNPCC) syndrome. Int J Cancer 1995; 64: 430-433.

14 Cramer DW, Hutchison GB, Welch WR, Scully RE, Ryan KJ. Determinants of ovarian cancer risk. I. Reproductive experiences and family history. J Natl Cancer Inst 1983; 71: 711-716.

15 Riman T, Dickman PW, Nilsson S, Correia N, Nordlinder H, Magnusson CM, et al. Risk factors for invasive epithelial ovarian cancer: results from a Swedish case-control study. Am J Epidemiol 2002; 156: 363-373

16 Whittemore AS, Harris R, Itnyre J. Characteristics relating to ovarian cancer risk: collaborative analysis of 12 US case-control studies. II. Invasive epithelial ovarian cancers in white women. Collaborative Ovarian Cancer Group. Am J Epidemiol 1992; 136: 1184-1203.

17 Purdie D, Green A, Bain C, Siskind V, Ward B, Hacker N, et al. Reproductive and other factors and risk of epithelial ovarian cancer: an Australian case-control study. Survey of Women's Health Study Group. Int J Cancer 1995; 62: 678-684.

18 Polychronopoulou A, Tzonou A, Hsieh CC, Kaprinis G, Rebelakos A, Toupadaki N, et al. Reproductive variables, tobacco, ethanol, coffee and somatometry as risk factors for ovarian cancer. Int $J$ Cancer 1993; 55: 402-407.

19 Hankinson SE, Colditz GA, Hunter DJ, Willett WC, Stampfer MJ, Rosner B, et al. A prospective study of reproductive factors and risk of epithelial ovarian cancer. Cancer 1995; 76: 284-290.

20 Booth M, Beral V, Smith P. Risk factors for ovarian cancer: a casecontrol study. Br J Cancer 1989; 60: 592-598.

21 Adami HO, Hsieh CC, Lambe M, Trichopoulos D, Leon D, Persson $\mathrm{I}$, et al. Parity, age at first childbirth, and risk of ovarian cancer. Lancet 1994; 344: 1250-1254.

22 Risch HA, Marrett LD, Howe GR. Parity, contraception, infertility, and the risk of epithelial ovarian cancer. Am J Epidemiol 1994; 140: 585-597.

23 Mosgaard BJ, Lidegaard O, Kjaer SK, Schou G, Andersen AN. Infertility, fertility drugs, and invasive ovarian cancer: a case-control study. Fertil Steril 1997; 67: 1005-1012.

24 Gwinn ML, Lee NC, Rhodes PH, Layde PM, Rubin GL. Pregnancy, breast feeding, and oral contraceptives and the risk of epithelial ovarian cancer. J Clin Epidemiol 1990; 43: 559-568.

25 Rosenblatt KA, Thomas DB. Lactation and the risk of epithelial ovarian cancer. The WHO Collaborative Study of Neoplasia and Steroid Contraceptives. Int J Epidemiol 1993; 22: 192-197.

26 The reduction in risk of ovarian cancer associated with oral- 


\section{REVIEW}

contraceptive use. The Cancer and Steroid Hormone Study of the Centers for Disease Control and the National Institute of Child Health and Human Development. N Engl J Med 1987; 316: 650-655.

27 Rosenberg L, Palmer JR, Zauber AG, Warshauer ME, Lewis JL Jr, Strom BL, et al. A case-control study of oral contraceptive use and invasive epithelial ovarian cancer. Am J Epidemiol 1994; 139: 654-661.

28 Hankinson SE, Colditz GA, Hunter DJ, Spencer TL, Rosner B, Stampfer MJ A quantitative assessment of oral contraceptive use and risk of ovarian cancer. Obstet Gynecol 1992; 80: 708-714.

29 Stanford JL. Oral contraceptives and neoplasia of the ovary. Contraception 1991; 43: 543-556.

30 Franceschi S, Parazzini F, Negri E, Booth M, La Vecchia C, Beral V, et al. Pooled analysis of 3 European case-control studies of epithelial ovarian cancer: III. Oral contraceptive use. Int J Cancer 1991; 49: 61-65.

31 Risch HA, Marrett LD, Jain M, Howe GR. Differences in risk factors for epithelial ovarian cancer by histologic type. Results of a casecontrol study. Am J Epidemiol 1996; 144: 363-372.

32 Rosenblatt KA, Thomas DB, Noonan EA. High-dose and low-dose combined oral contraceptives: protection against epithelial ovarian cancer and the length of the protective effect. The WHO Collaborative Study of Neoplasia and Steroid Contraceptives. Eur J Cancer 1992; 28A: 1872-1876.

33 Liang AP, Levenson AG, Layde PM, Shelton JD, Hatcher RA, Potts $\mathrm{M}$, et al. Risk of breast, uterine corpus, and ovarian cancer in women receiving medroxyprogesterone injections. JAMA 1983; 249: 2909-2912.

34 Modan B, Hartge P, Hirsh-Yechezkel G, Chetrit A, Lubin F, Beller U, et al. Parity, oral contraceptives, and the risk of ovarian cancer among carriers and noncarriers of a BRCA1 or BRCA2 mutation. $N$ Engl J Med 2001; 345: 235-240.

35 Narod SA, Risch H, Moslehi R, Dorum A, Neuhausen S, Olsson H, et al. Oral contraceptives and the risk of hereditary ovarian cancer. Hereditary Ovarian Cancer Clinical Study Group. $N$ Engl J Med 1998; 339: 424-428.

36 Whittemore AS, Balise RR, Pharoah PD, Dicioccio RA, OakleyGirvan I, Ramus SJ, et al. Oral contraceptive use and ovarian cancer risk among carriers of BRCA1 or BRCA2 mutations. $\mathrm{Br} J$ Cancer 2004; 91: 1911-1915

37 Mosgaard BJ, Lidegaard O, Kjaer SK, Schou G, Andersen AN. Ovarian stimulation and borderline ovarian tumors: a case-control study. Fertil Steril 1998; 70: 1049-1055.

38 Parazzini F, Negri E, La Vecchia C, Moroni S, Franceschi S, Crosignani PG. Treatment for infertility and risk of invasive epithelial ovarian cancer. Hum Reprod 1997; 12: 2159-2161.

39 Dor J, Lerner-Geva L, Rabinovici J, Chetrit A, Levran D, Lunenfeld $\mathrm{B}$, et al. Cancer incidence in a cohort of infertile women who underwent in vitro fertilization. Fertil Steril 2002; 77: 324-327.

40 Doyle P, Maconochie N, Beral V, Swerdlow AJ, Tan SL. Cancer incidence following treatment for infertility at a clinic in the UK. Hum Reprod 2002; 17: 2209-2213.

41 Venn A, Watson L, Bruinsma F, Giles G, Healy D. Risk of cancer after use of fertility drugs with in-vitro fertilisation. Lancet 1999; 354 1586-1590.

42 Lacey JV Jr, Mink PJ, Lubin JH, Sherman ME, Troisi R, Hartge P, et al. Menopausal hormone replacement therapy and risk of ovarian cancer. JAMA 2002; 288: 334-341.

43 Rodriguez C, Patel AV, Calle EE, Jacob EJ, Thun MJ. Estrogen replacement therapy and ovarian cancer mortality in a large prospective study of US women. JAMA 2001; 285: 1460-1465.

44 Riman T, Dickman PW, Nilsson S, Correia N, Nordlinder H, Magnusson CM, et al. Hormone replacement therapy and the risk of invasive epithelial ovarian cancer in Swedish women. J Natl Cancer Inst 2002; 94: 497-504.

45 Anderson GL, Judd HL, Kaunitz AM, Barad DH, Beresford SA, Pettinger M, et al. Effects of estrogen plus progestin on gynecologic cancers and associated diagnostic procedures: the Women's Health Initiative randomized trial. JAMA 2003; 290: 1739-1748.

46 Graham J, Graham R. Ovarian cancer and asbestos. Environ Res 1967; 1: 115-128.

47 Venter PF, Iturralde M. Migration of a particulate radioactive tracer from the vagina to the peritoneal cavity and ovaries. S Afr Med J 1979; 55: 917-919.

48 Cramer DW, Liberman RF, Titus-Ernstoff L, Welch WR, Greenberg $\mathrm{ER}$, Baron JA, et al. Genital talc exposure and risk of ovarian cancer. Int J Cancer 1999; 81: 351-356.
49 Vessey MP, Painter R. Endometrial and ovarian cancer and oral contraceptives - findings in a large cohort study. Br J Cancer 1995; 71: $1340-1342$

50 Miracle-McMahill HL, Calle EE, Kosinski AS, Rodriguez C, Wingo $\mathrm{PA}$, Thun MJ, et al. Tubal ligation and fatal ovarian cancer in a large prospective cohort study. Am J Epidemiol 1997; 145: 349-357.

51 Green A, Purdie D, Bain C, Siskind V, Russell P, Quinn M, et al. Tubal sterilisation, hysterectomy and decreased risk of ovarian cancer. Survey of Women's Health Study Group. Int J Cancer 1997; 71: $948-951$.

52 Kreiger N, Sloan M, Cotterchio M, Parsons P. Surgical procedures associated with risk of ovarian cancer. Int J Epidemiol 1997; 26: $710-715$

53 Hankinson SE, Hunter DJ, Colditz GA, Willett WC, Stampfer MJ, Rosner B, et al. Tubal ligation, hysterectomy, and risk of ovarian cancer. A prospective study. JAMA 1993; 270: 2813-2818.

54 Ogawa S, Kaku T, Amada S, Kobayashi H, Hirakawa T, Ariyoshi K, et al. Ovarian endometriosis associated with ovarian carcinoma: a clinicopathological and immunohistochemical study. Gynecol Oncol 2000; 77: 298-304

55 Takahashi K, Kurioka H, Irikoma M, Ozaki T, Kanasaki H, Miyazaki $\mathrm{K}$. Benign or malignant ovarian neoplasms and ovarian endometriomas. J Am Assoc Gynecol Laparosc 2001; 8: 278-284.

56 Vercellini P, Parazzini F, Bolis G, Carinelli S, Dindelli M, Vendola N, et al. Endometriosis and ovarian cancer. Am J Obstet Gynecol 1993; 169: $181-182$.

57 Schildkraut JM, Schwingl PJ, Bastos E, Evanoff A, Hughes C. Epithelial ovarian cancer risk among women with polycystic ovary syndrome. Obstet Gynecol 1996; 88(4 Pt 1): 554-559.

58 Balen A. Polycystic ovary syndrome and cancer. Hum Reprod Update 2001; 7: 522-525.

59 Risch HA, Howe GR. Pelvic inflammatory disease and the risk of epithelial ovarian cancer. Cancer Epidemiol Biomarkers Prev 1995; 4: 447-451.

60 Parazzini F, La Vecchia C, Negri E, Moroni S, dal Pino D, Fedele L. Pelvic inflammatory disease and risk of ovarian cancer. Cancer Epidemiol Biomarkers Prev 1996; 5: 667-669.

61 Ness RB, Grisso JA, Cottreau C, Klapper J, Vergona R, Wheeler JE, et al. Factors related to inflammation of the ovarian epithelium and risk of ovarian cancer. Epidemiology 2000; 11: 111-117.

62 Hisada M, van den Berg BJ, Strickler HD, Christianson RE, Wright WE, Waters DJ, et al. Prospective study of antibody to human papilloma virus type 16 and risk of cervical, endometrial, and ovarian cancers (United States). Cancer Causes Control 2001; 12: 335-341.

63 Risch HA, Jain M, Marrett LD, Howe GR. Dietary lactose intake, lactose intolerance, and the risk of epithelial ovarian cancer in southern Ontario (Canada). Cancer Causes Control 1994; 5: $540-548$.

64 La Vecchia C, Decarli A, Negri E, Parazzini F, Gentile A, Cecchetti $\mathrm{G}$, et al. Dietary factors and the risk of epithelial ovarian cancer. $J$ Natl Cancer Inst 1987; 79: 663-669.

65 Kushi LH, Mink PJ, Folsom AR, Anderson KE, Zheng W, Lazovich $\mathrm{D}$, et al. Prospective study of diet and ovarian cancer. Am J Epidemiol 1999; 149: 21-31

66 Fairfield KM, Hankinson SE, Rosner BA, Hunter DJ, Colditz GA, Willett WC. Risk of ovarian carcinoma and consumption of vitamins $\mathrm{A}, \mathrm{C}$, and $\mathrm{E}$ and specific carotenoids: a prospective analysis. Cancer 2001; 92: 2318-2326.

67 Purdie DM, Bain CJ, Webb PM, Whiteman DC, Pirozzo S, Green AC. Body size and ovarian cancer: case-control study and systematic review (Australia). Cancer Causes Control 2001; 12: 855-863.

68 Kuper H, Cramer DW, Titus-Ernstoff L. Risk of ovarian cancer in the United States in relation to anthropometric measures: does the association depend on menopausal status? Cancer Causes Control 2002; 13: 455-463.

69 Lubin F, Chetrit A, Freedman LS, Alfandary E, Fishler Y, Nitzan H, et al. Body mass index at age 18 years and during adult life and ovarian cancer risk. Am J Epidemiol 2003; 157: 113-120.

70 Lukanova A, Toniolo P, Lundin E, Micheli A, Akhmedkhanov A, Muti $\mathrm{P}$, et al. Body mass index in relation to ovarian cancer: a multicentre nested case-control study. Int J Cancer 2002; 99: 603-608.

71 Engeland A, Tretli S, Bjorge T. Height, body mass index, and ovarian cancer: a follow-up of 1.1 million Norwegian women. J Natl Cancer Inst 2003; 95: 1244-1248.

72 Fairfield KM, Willett WC, Rosner BA, Manson JE, Speizer FE, Hankinson SE. Obesity, weight gain, and ovarian cancer. Obstet Gynecol 2002; 100: 288-296. 